\title{
Study of Drug Utilization on Acute Poisoning Cases Treated at Tertiary Care Hospital
}

\author{
Dr. Sreya Todi \\ Assistant Professor, Department of Pharmacology, \\ CIMS Medical College, Bilaspur
}

Address of correspondence - Dr. Sreya Todi

\begin{abstract}
Acute poisoning is common everywhere in medical emergency. Acute poisoning may be due to deliberate exposure to drugs, chemicals and natural toxins or accidental which is emergency for common medical health. The main aim of this study was to investigate the pattern of drug utilization, poisoning agents, and outcome in patients with treated acute poisoning. Material and Methods: This prospective cross sectional study was carried out in the emergency department of a tertiary care centre over a one year period. Result: During the period of 1 year total 310 Acute poisoning cases were recorded by us. Out of 310 acute poisoning cases 170(54.8\%) were male where as females were 140(45.2\%). The majority of cases were from age group of 20 -50 years in males whereas mean age of female patients was 37.3 years and majority of the cases were from 25-50 age group. The most common route of exposure to poisons (69.6\%) was ingestion and followed by dermal exposure (in cases of venomous animal exposures) (25.8\%) and inhalation (4.6\%).The most common symptomatic treatments given to the patients were antimicrobials (88.7\% of cases), antiemetics (82.6\%\% of cases), H2 blockers (72.9\% of cases) and Atropine (51\% of cases), pralidoxime (41.6\% of cases) Proton pump inhibitors and Vasopressor agents etc respectively. The most commonly prescribed specific antidotes were Anti-snake venom (ASV) (12.9\% of cases).Conclusion: In the present study, the main causes of poisoning were identified as household products in urban areas of India. Awareness about the dangers of such poisons should be the added responsibility of health and hospital authorities. Poison control center establishment in the region will also help in preventing and controlling such poisoning events.
\end{abstract}

Keywords: Drugs, Poison, organophosphorus compound, Household Products, India

\section{Introduction}

In the field of the human health Acute poisoning is also one of the common medical emergencies. Acute poisoning may be due to deliberate exposure to drugs, chemicals and natural toxins or accidental which is an emergency for common medical health services. Acute poisoning is a major health problem worldwide with significant mortality and morbidity affecting all age groups of people. In the developing world, Poisoning is a major public health problem resulting in hospitalization and health threats leading to prominent financial load on patients and an immense pressure on hospital services. According to the previous reports about 700 people die every day from poisonings and several thousands are more affected by poisoning around the world. ${ }^{[1,2,3]}$ According to national annual report of India in 2012, 110,688 people died due to poisoning. In the year 2012, according to data from National Crime Bureau of India $7.8 \%$ of all causes of un-natural deaths are for accidental poisoning. In the same year $2012,29.5 \%$ of suicidal deaths were observed for poison ingestion for committing suicide $^{[4]}$ The measure of the problem can be explained by regionwise or countrywise epidemiological studies. ${ }^{[5]}$

The pattern of poisoning differ from region to region and country to country depending on factors like geography, availability of poison, accessibility, socio-economic conditions, cultural and religious influences. In developed countries such as Norway, paracetamol, ethanol and benzodiazepines are the most common causes of poisoning. ${ }^{[6]}$ In India the majority of the population is employed in agriculture, due to more uses of pesticides and agrochemical products poisoning is more common. ${ }^{[7]}$ In India, an acute poisoning case is one of the most common causes of emergency hospital admissions. It has been reported that approximately constitutes $10 \%$ acute poisoning cases of admissions in medical emergency departments. ${ }^{[8]}$ The management of acute poisonings cases depends upon availability of healthcare facilities, institutional protocols and life-saving drugs. Every academic medical institutional sector has to manage for regularly evaluate drug utilization in different departments and review institutional therapeutic protocols to rationalize drug use and enhance patients' outcome. ${ }^{[9]}$ There is also necessary to evaluate annual epidemiologic data on acute poisonings treated cases at each medical sector for better handle and manage antidote stock and drugs. ${ }^{[10]}$ Therefore this study was done for investigate the pattern of drug utilization, poisoning agent and treated of acute poisoning cases with outcomes.

\section{Materials and Methods}

This study was conducted in the Dept. of Pharmacology at Institute of Postgraduate Medical Education and Research, Kolkata. The study was carried out for the period of 1 year in 2015 to 2016. Patients included in this study were those who admit poisoned patients initially, admitted to emergency department and also 


\section{International Journal of Innovative Research in Medical Science (IJIRMS) Volume 03 Issue 10 Oct 2018, ISSN: 2455-8737, Imp. Factor - 4.102 \\ Available online at $-\underline{w w w . i j i r m s . i n}$}

admits referrals (severe poisoned patients) from secondary care hospitals and private hospitals in this region. On the basis of history, clinical findings and in some cases through routine laboratory investigations was made for diagnosis. Those patients with 10 years of age and uncertain diagnosis were excluded from the study. From institutional ethics committee for human research and related committee approval was taken before initiating study. The confidentiality of patient's personal information was maintained.

In this study data such as age, duration of hospital stay, clinical findings, final diagnosis, treatments delivered and final outcomes were taken from the case papers during their admission in the hospital. Also drugs prescribed for patients by brand names and for fixed dose combinations, the information about generic name of the drugs and contents of formulations were obtained from the 2013 edition of Indian Drug Review and the 2013 edition of Current Index of Medical Specialties.

\section{Observations and Results}

During the period of 1 year total 310 Acute Poisoning Cases were recorded by us at a tertiary care centre. Out of 310 acute poisoning cases $170(54.8 \%)$ were male where as females were $140(45.2 \%)$. ICH Mean age of the patients was 28.3 years which belong to age group $20-30$ years. The majority of cases were from age group of $20-50$ years in males whereas mean age of female patients was 23.3 years and majority of the cases were from age group which was equivalent to male as shown in table no 1 . Most of the patients reside in urban areas and maximum numbers of patients were Hindus followed by Muslims.A highest frequency of poisoning was seen in unmarried cases.

Table 1: Number of poisonings by age group and sex

\begin{tabular}{|c|c|c|c|c|}
\hline \multirow{2}{*}{$\begin{array}{c}\text { Age group } \\
\text { (in years) }\end{array}$} & \multicolumn{2}{|c|}{ Sex } & \multirow{2}{*}{ Total } & $\begin{array}{c}\text { Percentage } \\
(\%)\end{array}$ \\
\cline { 2 - 5 } & Male & Female & & 5.5 \\
\hline $\mathbf{1 0 - 2 0}$ & 12 & 5 & 17 & 20.6 \\
\hline $\mathbf{2 0 - 3 0}$ & 36 & 28 & 64 & 15.2 \\
\hline $\mathbf{3 0 - 4 0}$ & 25 & 22 & 47 & 35.2 \\
\hline $\mathbf{4 0 - 5 0}$ & 58 & 51 & 109 & 19.4 \\
\hline $\mathbf{5 0 - 6 0}$ & 32 & 28 & 60 & 4.2 \\
\hline $\mathbf{6 0 - 7 0}$ & 7 & 6 & 13 & 100 \\
\hline Total & 170 & 140 & 310 & \\
\hline
\end{tabular}

The most common route of exposure to poisons (69.6\%) was ingestion and followed by dermal exposure (in cases of venomous animal exposures) $(25.8 \%)$ and inhalation (4.6\%). Intentional (suicidal) was the most common mode of poisoning, which was observed in $65.1 \%$ of cases while accidental poisoning accounted for $34.9 \%$ of cases. Table no 2 shows different causative poisoning agents which were observed during this study. The most common causes of poisoning cases were pesticides $(40.6 \%)$, followed by Venomous animal exposures $25.8 \%$ and Household agents (18.7\%) respectively. Venomous animal exposures included snake bites, honey bee stings, and unknown bites and stings. In $7.4 \%$ of cases, the poisoning agents could not be identified. Vomiting, dizziness, difficulty in breathing, abdominal pain, local punctures and bite marks in venomous animal exposures etc were observed symptoms in the patients.
Table 2: Poisoning agents of acute poisoning cases

\begin{tabular}{|l|c|c|}
\hline Poisoning agents & Number & $\begin{array}{c}\text { Percentage } \\
(\boldsymbol{\%})\end{array}$ \\
\hline Household agents & $\mathbf{5 8}$ & 18.7 \\
\hline Hydrocarbons & 50 & 16.1 \\
\hline Cosmetic & 3 & 1.0 \\
\hline Corrosive agents3 & 5 & 1.6 \\
\hline Pesticides & $\mathbf{1 2 6}$ & 40.6 \\
\hline Organophosphates & 68 & 21.9 \\
\hline Variable insecticides & 30 & 9.7 \\
\hline Rodenticides & 24 & 7.7 \\
\hline Herbicides & 2 & 0.6 \\
\hline Aluminum phosphide & 1 & 0.3 \\
\hline Organophosphate + pyrethroid & 1 & 0.3 \\
\hline Venomous animal exposures & 80 & 25.8 \\
\hline Drugs & 15 & 4.8 \\
\hline Insecticide + Kerosene & 3 & 1.0 \\
\hline Food poisoning & 2 & 0.6 \\
\hline Unknown compounds & 23 & 7.4 \\
\hline Total & 310 & 100 \\
\hline
\end{tabular}

Table no 2 showing various Poisoning agents of acute poisoning cases. Poisoning agents number of cases and its percentage show in above table.

Table 3: Medicines prescribed for acute poisoning cases

\begin{tabular}{|l|c|c|}
\hline Medicines & Number & Percentage (\%) \\
\hline As Specific Antidote & \multicolumn{2}{|l|}{} \\
\hline Atropine & 158 & 51.0 \\
\hline Pralidoxime & 129 & 41.6 \\
\hline Anti-snake venom & 40 & 12.9 \\
\hline Neostigmine** & 9 & 2.9 \\
\hline Physostigmine*** & 1 & 0.3 \\
\hline As Symptomatic Treatment & \multicolumn{2}{|l|}{} \\
\hline Antiemetic & 256 & 82.6 \\
\hline H2 blockers* & 226 & 72.9 \\
\hline Antimicrobials & 275 & 88.7 \\
\hline Proton pump inhibitors* & 105 & 33.9 \\
\hline Vasopressor agents & 74 & 23.9 \\
\hline Tetanus toxoid & 68 & 21.9 \\
\hline Analgesics & 42 & 13.5 \\
\hline Anticonvulsants & 31 & 10.0 \\
\hline Glucocorticoids & 24 & 7.7 \\
\hline Benzodiazepine & 21 & 6.8 \\
\hline Antihistamines & 16 & 5.2 \\
\hline Calcium & 12 & 3.9 \\
\hline Bronchodilators & 8 & 2.6 \\
\hline Diuretics & 5 & 1.6 \\
\hline
\end{tabular}

Table no: 3 shows the most common symptomatic treatments given to the patients were antimicrobials ( $88.7 \%$ of cases) antiemetics (82.6\%\% of cases), $\mathrm{H} 2$ blockers (72.9\% of cases) and Atropine (51\% of cases), pralidoxime (41.6\% of cases) Proton pump inhibitors and Vasopressor agents etc respectively. The most commonly prescribed specific antidotes were Anti-snake venom (ASV) (12.9\% of cases). As nutritional supplements, different 


\section{International Journal of Innovative Research in Medical Science (IJIRMS) Volume 03 Issue 10 Oct 2018, ISSN: 2455-8737, Imp. Factor - 4.102 \\ Available online at - $w w w . i j i r m s . i n$}

vitamin and enzyme preparations were also prescribed for patients, respectively.

Parenteral route was the most common route used for drug administration. Only 20 patients received drugs orally. Different drugs were prescribed including generic name and which were prescribed by brand name.

Mean duration of hospital stay was $6 \pm 4$ days with a median of 4 days. Maximum length of hospital stay was observed in a case of acid ingestion. Table no: 4shows outcome of patients in which complete recovery was seen in $47.4 \%$ of cases and mortality rate was $23.2 \%$. Out of 72 death cases, suicidal poisoning were 38 and accidental poisoning were 6due which shows a statistically significant difference. Due to unknown compounds (14 cases), OP agents ( 5 cases), snakebites ( 2 cases), unclassified insecticides ( 3 cases), corrosive agents (1case), aluminum phosphide (1 case), ethanol (2cases) deaths were also recorded.

Table 4: Acute poisoning cases with its outcome

\begin{tabular}{|l|c|c|}
\hline Outcome cases & Number & $\begin{array}{c}\text { Percentage } \\
(\boldsymbol{\%})\end{array}$ \\
\hline Complete recovery & 147 & 47.4 \\
\hline Discharge against medical advice & 66 & 21.3 \\
\hline Absconded & 25 & 8.1 \\
\hline Death & 72 & 23.2 \\
\hline Total & 310 & 100 \\
\hline
\end{tabular}

\section{Discussion}

In Emergency Departments of hospitals arrival of Poisoning cases are very common in India. The research shows that per month on an average 38 cases are reported and this is due to occupational exposures mainly ones involved in agriculture, easy availability of toxic agents and no awareness particularly in rural areas. ${ }^{[11]}$ In this study, a male predominance was observed which shows similar pattern by other studies in India as Mittal N et.al, Gupta P et.al and Ramesh V et.al. ${ }^{[12,13,14]}$ Due to increased occupational hazard, as well as love matter and exposure of men to stress being the earning member compared was to women may be the trend for this. In this study, most of the cases were between 20 to 50 years of age group which was similar to the other studies in India and may due to love ,domestic, educational and employment related stress. ${ }^{[13,14,15]}$ It is a known fact that adolescents and young adults are more prone to poisoning due to emotional problems, economical stress, work pressure, marriage, quarrel with family, and other life settlement factors. ${ }^{[16]}$ In this study, the most common poisoning agents were pesticides which were similar to Maharani et al studied similarly reported pesticides as the most common poisoning agent in Tamil Nadu, southern India. ${ }^{[17]}$ According to the Studies conducted in Nepal and Bangladesh also ascertained pesticides as the commonest toxic agent used for poisoning. ${ }^{[18,19]}$

Ommon irrationally antimicrobials agents are used as medicines in low and middle income countries. ${ }^{[20]}$ An antibiotic resistance poses a serious threat to humans and subverts global economy. It is unaccountable that high usage of antibiotics exists in a poisoning ward. Various clinical trials did not prove any benefit of antibiotic therapy for acute poisonings especially in organophosphate poisoning and snakebites. ${ }^{[21,22]}$ In this study High mortality could be because of various reasons like lack of information regarding the poison agent and the dose/amount consumed in some cases, long time interval between toxic exposure and hospital arrival, highly toxic pesticide ingestions, lethal snakebite envenomations and finally lack of specific antidotes. Many patients were referred when their conditions had become worse from hospitals with a delay. The majority of the patients recovered, indicates good emergency and intensive care management in our setting. Therefore morbidity and mortality will help decrease poisoning center in tertiary care hospitals.

\section{Conclusion}

In the present study, the main causes of poisoning were identified household products in urban areas of India. This finding emphasis that education of the general people about the risk of poisoning at home. There should be creating awareness about the dangers of such poisons in health and hospital authorities. Poison control center establishment in the region will also help in preventing and controlling such poisoning events. Educational programs for preventive measures for toxic exposures are necessary to create awareness among the public.

\section{References}

[1] Aravind A, Rai M. Pattern of Acute Poisoning Admissions in the Medical Intensive Care Unit of a Tertiary Care Hospital. Int J Pharm Sci Drug Res 2014;6:239-42.

[2] Zine KU, Mohanty AC. Pattern of acute poisoning at Indira Gandhi Medical College and Hospital, Nagpur. J Indian Acad Forensic Med 1998;20:37-9.

[3] International Programme on Chemical Safety, World Health Organization. Guidelines for poison control. Geneva, Switzerland: WHO press; 1997.

[4] National Crime Records Bureau, Ministry of Home Affairs. Accidental Deaths and Suicides in India - 2012. New Delhi: NCRB; 2012.

[5] Kora SA, Doddamani GB, Halagali GR, Vijayamahantesh SN, Boke U. Sociodemographic Profile of the Organophosphorus Poisoning Cases in Southern India. J Clin Diagn Res 2011;5(5):953-6.

[6] Hovda KE, Bjornaas MA, Skog K, Opdahl A, Drottning $\mathrm{P}$, Ekeberg $\mathrm{O}$, et al. Acute poisonings treated in hospitals in Oslo: a one-year prospective study (I): pattern of poisoning. Clin Toxicol (Phila) 2008 Jan;46(1):35-41.

[7] Ramesha KN, Rao KB, Kumar GS. Pattern and outcome of acute poisoning cases in a tertiary care hospital in Karnataka, India. Indian $\mathbf{J}$ Crit Care Med 2009;13(3):152-5.

[8] Sharma BR, Harish D, Sharma V, Vij K. Poisoning in Northern India: Changing trends, causes and prevention thereof. Med Sci Law 2002; 42(3):251-7.

[9] WHO International Working Group for Drug Statistics Methodology, WHO Collaborating Centre for Drug Statistics Methodology, WHO Collaborating Centre for Drug Utilization Research and Clinical Pharmacological Services. Introduction to drug utilization research. Oslo, Norway: WHO Press; 2003.

[10] WHO International Working Group for Drug Statistics Methodology, WHO Collaborating Centre for Drug Statistics Methodology, WHO Collaborating Centre for Drug Utilization Research and Clinical Pharmacological 
Services. Introduction to drug utilization research. Oslo, Norway: WHO Press; 2003.

[11] Singh NP, Kaur G. Poisoning: Basic Considerations and Epidemiology. In: Munjal YP, Sharma SK, Agarwal AK, Gupta P, Kamath SA, Nadkar MY, et al, editors. API Textbook of Medicine. 9th Ed. New Delhi, India: Jaypee Brothers Medical Pub; 2012.

[12] Mittal N, Shafiq N, Malhotra S, Bhalla A, Pandhi P. A prospective observational study on different poisoning cases and their outcomes in a tertiary care hospital. SAGE Open Med. 2013; 1.

[13] Gupta P, Kumar A, Singh SP, Prakash M, Gupta M, Kumar P. Pattern of Cases of Acute Poisoning in a Rural Tertiary Care Center in Northern India. National J Commun Med. 2016; 7: 307-310

[14] Ramesh V, Chavan VR, Arshad M, Raghunandan M, Faizuddin. A Study on Pattern of Acute Poisoning in an Emergency Department of a Tertiary Care Hospital. Asian J Pharm Clin Res. 2016; 9: 361-363.

[15] Naresh DTV, Shailendra D, Subbaratnam Y, Prasuna G, Rajashekar K, Mary Rohini. Profile of Poisoning Cases in Tertiary Care Hospital, Telangana, India. J Evidence Based Med Hlthcare. 2015; 2: 3032-3038.

[16] Bari MS, Chakraborty SR, Alam MMJ, Qayyum JA, Hassan N, Chowdhury FR. Four-Year Study on Acute Poisoning Cases Admitted to a Tertiary Hospital in
Bangladesh: Emerging Trend of Poisoning in Commuters. Asia Pac J Med Toxicol 2014;3:152-6.

[17] Maharani B, Vijayakumari N. Profile of poisoning cases in a tertiary care Hospital, Tamil Nadu, India. J Appl Pharm Sci 2013;3:91-4.

[18] Marahatta SB, Singh J, Shrestha R, Koju R. Poisoning cases attending emergency department in Dhulikhel HospitalKathmandu University Teaching Hospital. Kathmandu Univ Med J (KUMJ) 2009;7:152-6

[19] Bari MS, Chakraborty SR, Alam MMJ, Qayyum JA, Hassan N, Chowdhury FR. Four-Year Study on Acute Poisoning Cases Admitted to a Tertiary Hospital in Bangladesh: Emerging Trend of Poisoning in Commuters. Asia Pac J Med Toxicol 2014;3:152-6.

[20] Afshari R. Non-medical Use of Medications in Middle and Low Income Countries. Asia Pac J Med Toxicol 2014;3:49

[21] Kularatne SA, Kumarasiri PV, Pushpakumara SK, Dissanayaka WP, Ariyasena H, Gawarammana IB, Senanayake N. Routine antibiotic therapy in the management of the local inflammatory swelling in venomous snakebites: results of a placebo-controlled study. Ceylon Med J 2005;50:151-5

[22] Priyendu A, Vandana KE, Varma M, Prabhu N, Rahim AA, Nagappa AN. Antibiotic prophylaxis in organophosphorus poisoning: A study of health and economic outcomes. Saudi Pharm J. Forthcoming 2016. 